\title{
Microstructure and Phase Composition of Titanium Coatings Plasma Sprayed with a Shroud
}

\author{
Hong Zhou $^{1 *}$, Zhi Liu' ${ }^{2}$ and Liancong Luo ${ }^{3}$ \\ ${ }^{1}$ Centre for Engineering, Waikato Institute of Technology, Hamilton 3240, New Zealand \\ ${ }^{2}$ Waikato Regional Council, Hamilton 3240, New Zealand \\ ${ }^{3}$ Nanjing Institute of Geography and Limnology, Nanjing 210008, China
}

\begin{abstract}
Excellent corrosion resistance has made titanium a preferred material for use in industry with harsh environments. Protective titanium coatings combined with cheap bulk materials are expected to enable sufficient corrosion protection and lower the cost. Plasma spray processing of titanium feedstock becomes a challenging topic of research as titanium powder particles have to experience high temperatures in the flight during the thermal spraying process in an open air environment. In this paper, plasma spraying of titanium has been carried out by using a shroud in order to shield molten particles from reacting with surrounding environment. Microstructure analyses on the titanium coatings were performed by using SEM, EDS and XRD. The results show that the shroud attachment is capable of withstanding high plasma temperatures; the as-sprayed shrouded titanium coating exhibits a similar phase composition as the pure titanium powder, and an enhanced microstructure with a lower porosity for the titanium coating plasma-sprayed with a shrouding system is observed.
\end{abstract}

\section{Introduction}

Titanium and its alloys are well recognized for their corrosion resistance and the high strength-to-density ratio [1-3]. Excellent corrosion resistance has made titanium a preferred material for use in industry with harsh environments because they offer a high chemical resistance against various corrosive media due to a dense self-sealing oxide layer formed immediately when exposed to an oxygen containing atmosphere [4-5].

Since corrosion attack is mainly limited to the outer region of a component, a promising approach to optimize both corrosion resistance and mechanical properties is the use of coating technologies. Protective titanium coatings combined with cheap bulk materials which can provide the strength and ductility are expected to enable sufficient corrosion protection and lower the cost. Thermal spraying is a generic coating technique whereby heat sources like electric arc discharge, combustion, and plasma are used to melt the powder feedstock or wire consumable, and then projected at speed onto a substrate to build up a coating [6-7], as shown in Fig. 1.

\footnotetext{
*Corresponding author: zhouhong.nz@gmail.com
} 
Production steps for titanium and its alloys have to be carried out carefully in an inert atmosphere condition for their affinity of oxygen and other gases. Plasma spray is considered to be the most flexible coating technique. However, air plasma spraying (APS) of corrosion-resistant coatings of titanium is difficult because an oxidation of the metal increases coating porosity and degrades coating properties. In order to prevent titanium from too much oxidation the spray process has to be carried out in vacuum or inert atmosphere. Within the thermal spray area, low pressure plasma spray (LPPS) or vacuum plasma spray (VPS) has been the promising technique used for titanium deposition thanks to its inert atmosphere and ability to form dense coatings with low porosity and oxygen content [8]. Corrosion resistance similar to that of bulk Ti has been reported if proper spraying parameters including the size of the feedstock powder are optimized [9-10]. However, this process has limitation of the size of components and is rather expensive.

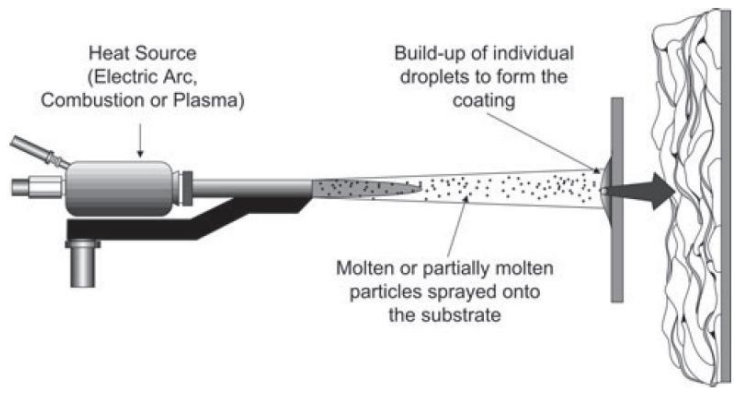

Fig. 1. Schematic diagram of coating formation process during thermal spray.

Shrouded plasma spray can be considered as a useful technology to produce low oxygen containing titanium coatings. This is to modify plasma spray torches by using an attachment onto an atmospheric plasma spraying torch [11-14]. In this work, plasma spraying of titanium has been carried out by using a shroud in order to shield molten particles from reacting with surrounding environment. Microstructure analyses on the plasma sprayed titanium coatings with/without a shrouding system were performed by using Scanning electron microscope (SEM), energy dispersive X-ray spectroscopy (EDS) and X-ray diffractometer (XRD).

\section{Experimental procedures}

\subsection{Shroud design}

A new design of shroud is proposed for plasma spray of titanium coatings, as presented in Fig. 2. The performance of a conventional conical shroud is not satisfactory due to the entrainment of air at the exit region [11]. The new design is based on a modification of the conventional shape by optimizing the profile of nozzle to a conical shape with a straight rear end. Transverse gas holes evenly distributed around the exit region help prevent air entrainment, and a large chamber for plasma jet is permitted to reduce a build-up of melted powders onto the inside wall of the shroud. A continuous circular slot at the end of shroud can make a continuous gas curtain around the plasma jet, and then further prevent the air entrainment. The new shroud was tested and plasma sprayed titanium coatings by using this shroud were fabricated. 


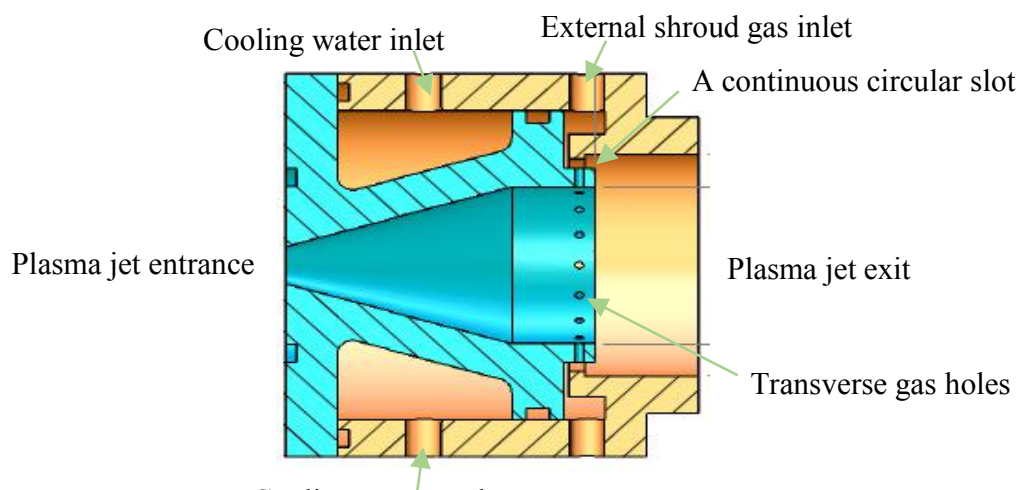

Cooling water outlet

Fig. 2. Schematic cross section illustrating the key features of the shroud.

\subsection{Materials}

Commercially available pure titanium powder (Xi'an Lilin International Trade Co., Ltd., Xi'an, China), with particle sizes range from $45 \mu \mathrm{m}$ to $75 \mu \mathrm{m}$ was used as feedstock powder for the titanium coating deposition. The titanium powder is made by hydridedehydride $(\mathrm{HDH})$ method. The chemical composition of HDH Ti powder is shown in table 1. Mild steel plates $(100 \mathrm{~mm} \times 25 \mathrm{~mm} \times 3 \mathrm{~mm})$ were used as the substrates which were degreased and sand blasted before depositing titanium coatings onto them.

Table 1. Chemical composition of HDH titanium powder.

\begin{tabular}{c|cccccc}
\hline Element & $\mathbf{H}$ & $\mathbf{O}$ & $\mathbf{N}$ & $\mathbf{C}$ & $\mathbf{F e}$ & $\mathbf{T i}$ \\
\hline HDH Ti powder & 0.23 & 0.35 & $<0.03$ & 0.07 & $<0.11$ & Bal \\
\hline
\end{tabular}

\subsection{Methods and microstructural characterization}

The titanium powder was then thermal sprayed by using a SG-100 plasma gun (Praxair surface technologies, USA). The novel shroud attachment was used for the shrouded plasma spraying process. The parameters for spraying with and without the shroud attachment were the same as indicated in table 2, except that there is a shroud gas in the shrouded plasma spraying process. The trial for spraying with the shroud used argon as a shrouding inert gas at the exit with a flow rate of $300 \mathrm{slpm}$.

Table 2. Spraying parameters for titanium coatings with and without a shroud.

\begin{tabular}{l|l}
\hline Spray parameter & setting \\
\hline Current, A & 800 \\
Voltage, V & 80 \\
Primary gas, Argon, slpm & 85 \\
Auxiliary gas, Helium, slpm & 18 \\
Powder feed rate, g/min & 30 \\
Spray passes & 10 \\
Spray distance, mm & 100 \\
Transverse speed, mm/s & 500 \\
Shroud gas, Argon, slpm & 300 \\
\hline
\end{tabular}


Cross sectional samples were metallographically prepared for microstructural analysis. Scanning electron microscope (SEM, Hitachi S4700, Japan) was used to observe the microstructures and morphology of specimens. An energy dispersive X-ray spectroscopy (EDS, Oxford INCA, UK) was used to detect the chemical compositions on a microscopic scale. Phase transformations were studied using an X-ray diffractometer (XRD, Bruker, model D8, Germany) with $\mathrm{CuK \alpha}$ radiation at $40 \mathrm{kV}$ and $30 \mathrm{~mA}$, the scanning speed of $2 \theta$ was $2^{\circ} \mathrm{min}^{-1}$ when measuring from $20^{\circ}-80^{\circ}$.

\section{Results and discussions}

\subsection{Phase composition}

The phase composition result of the titanium feedstock powder is shown in Fig. 3a. From the XRD pattern, it can be found that the HDH titanium powder is merely composed of $\alpha-$ Ti phase. Fig. $3 b$ and $3 c$ present the XRD patterns for titanium coatings with/without the shroud system. For the unshrouded titanium coating, it is composed of a mixture of phases including $\alpha-\mathrm{Ti}, \mathrm{TiO}$ and $\mathrm{TiN}$. The result indicates that oxidation and nitrodization occurred on the pure titanium particles at high temperatures during the air plasma spraying process. As there is no shroud protection, the oxide or/and nitride might be formed when the oxygen and nitrogen from surrounding air came in contact and reacted with molten titanium particles in flight. From the point of melting in the plasma until impact on the substrate, each molten or partially molten particle is prone to oxygen/nitrogen absorption/dissolution and oxidizing gas-liquid metal oxidation reactions. Oxygen/nitrogen from the entrained air is dissociated into highly reactive monotonic oxygen/nitrogen at high temperatures. This enable titanium particles oxidation/nitrodization to occur in a very short time. Oxidation may also take place during splat formation and coating build-up, even after solidification of the splats since the surface of each hot splat is prone to oxidation by the high temperature.

a)

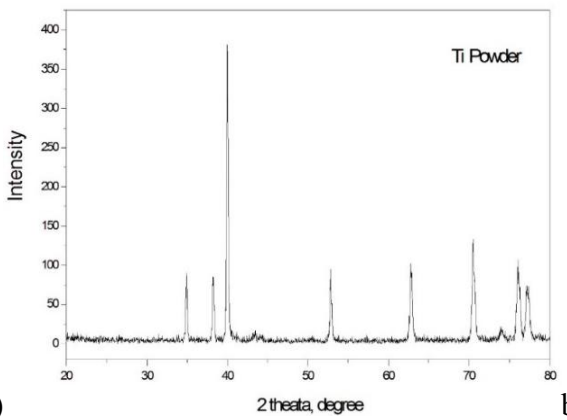

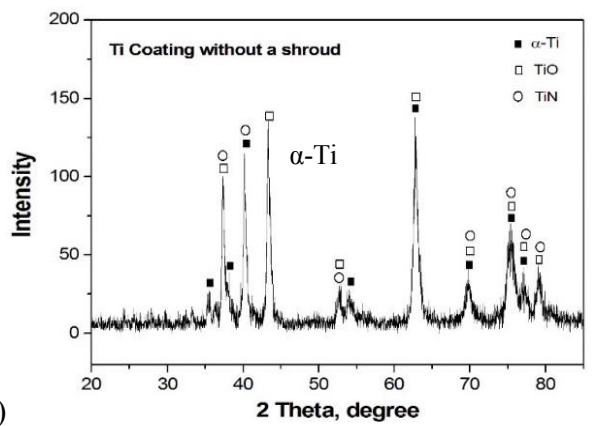

b)

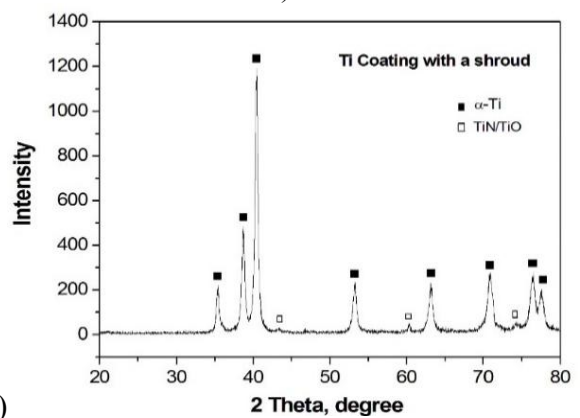

c)

Fig. 3. XRD patterns of the titanium powder (a) and titanium coatings plasma-sprayed in air without (b)/ with (c) the shroud. 
However, for the titanium coating plasma-sprayed with a shrouding system, the XRD pattern presents a similar curve as that for the pure titanium powder. The result reveals that the dominant phase in the shrouded titanium coating plasma-sprayed is still composed of a - Ti, which means that lower oxygen content in the shrouded titanium coating is obtained. Meanwhile, some very weak peaks for oxide and nitride of titanium can be found from the pattern, which means that there might exist a trace of oxide and nitride in the shrouded titanium coatings.

\subsection{Microstructure}

Fig. 4 presents the second electron images of polished cross sections of the titanium coatings with/without the shroud. The SEM images reveal that the shrouded titanium coating has a dense microstructure with a very low porosity; whereas the air plasma sprayed titanium coating possesses a high porosity. The presence of the shroud leads to a significant reduction in coating porosity. In principle the reduction in air entrainment with the shroud was expected to result in a better heating of the particles and then more molten titanium particles at higher temperatures in flight were obtained, which help decrease the porosity in the titanium coatings. As we know, the attachment itself shielded the plasma jet as it exited the spray gun in the shrouded plasma spraying process, and then a gas shroud enveloped the plasma jet as it left the attachment. The additional inert shroud gas was injected around and enveloped the plasma jet, shielding the molten particles from reacting with the surrounding environment, reducing the amount of entrainment of cold and heavy ambient air and delaying the corresponding drop in velocity and temperature, and thus retarded particle cooling and reduced oxygen content and porosity of the resulting coatings. Meanwhile, gas-shrouded nozzles could extend the hot core of the jet by rearranging the gas flow to increase the dwell time of particles in the plasma.

a)

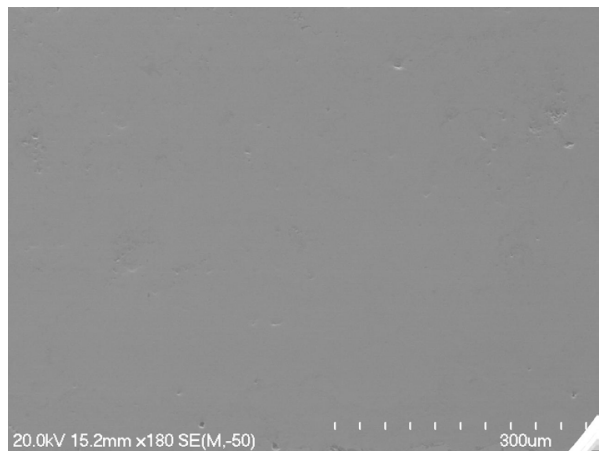

b)

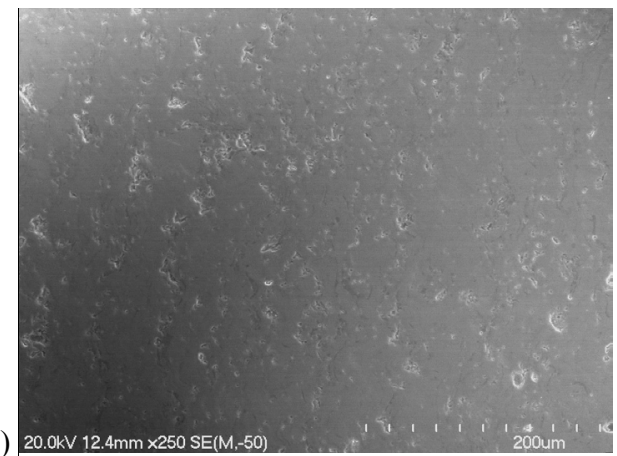

Fig. 4. SEM images for plasma sprayed Ti coatings with (a) and without (b) the shrouded.

Fig. 5 shows the SEM morphologies and element area compositions of the air/shrouded plasma sprayed titanium coatings, which was determined by EDS. The Ti and O contents of air/shrouded plasma sprayed titanium coatings are given in table 3. The EDS analyses indicate that the shrouded titanium coating presents an ideal pure titanium, and oxide and nitride were not found in the area assessed by EDS. However, oxygen element with $18.04 \pm 1.28$ weight $\%$ is determined in the air plasma sprayed titanium coating, titanium is $81.12 \pm 1.28$ weight $\%$, and other elements take the balance. This result also verifies that oxidation occurred in the air plasma spraying process; and the shrouding system provides an effective shielding to prevent oxidation from surrounding air entrainment. 
Table 3. Ti and O contents of titanium coatings determined by EDS.

\begin{tabular}{ccccc}
\hline & \multicolumn{2}{c}{ Shrouded } & \multicolumn{2}{c}{ Unshrouded } \\
\cline { 2 - 5 } Element & $\boldsymbol{T i}$ & $\boldsymbol{O}$ & $\boldsymbol{T i}$ & $\boldsymbol{O}$ \\
\hline Weight $\%$ & 100.00 & 0 & 81.12 & 18.04 \\
Weight $\%$ Error (+/- 1 Sigma) & $+/-0.75$ & - & $+/-0.75$ & $+/-1.28$ \\
\hline
\end{tabular}

a)

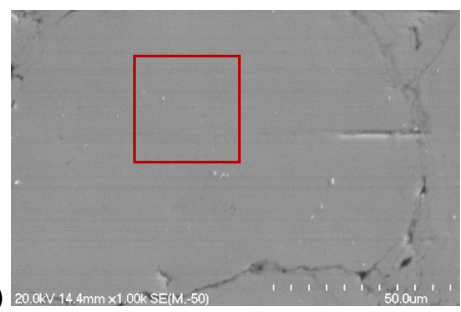

b)

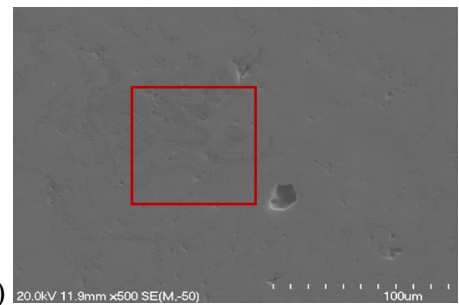

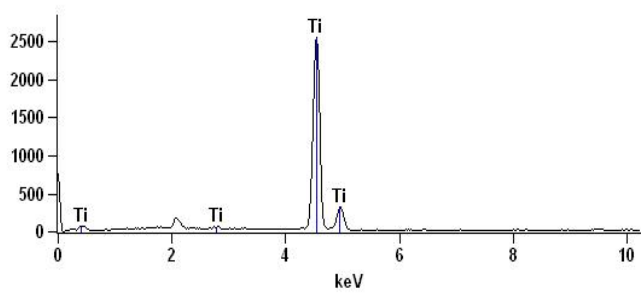

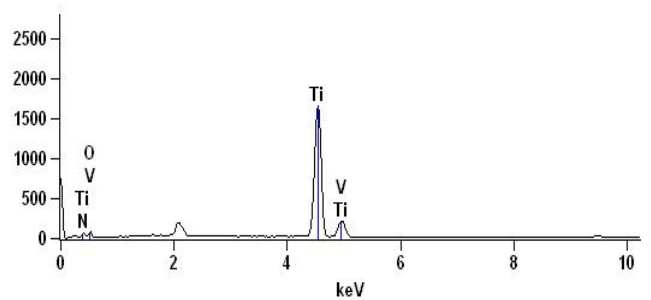

Fig. 5. SEM morphology and element area compositions of the air (a)/shrouded (b) plasma sprayed titanium coatings.

\section{Conclusions}

Titanium and titanium alloys have been used more and more for corrosion protection. Plasma spraying with a shrouded is a useful technology to produce low oxygen containing titanium coatings. The results show that the shroud attachment is capable of withstanding high plasma temperatures; oxidation and nitrodization occur on the pure titanium particles at high temperatures when the powder feedstock is air plasma-sprayed; the as-sprayed shrouded titanium coating exhibits a similar phase composition as the pure titanium powder, which means that a lower oxygen content in the shrouded titanium coating is obtained; and an enhanced microstructure with a lower porosity for the titanium coating plasma-sprayed with a shrouding system is observed, the shroud lead to a significant reduction in coating porosity.

\section{References}

1. C.Leyens, M.Peters, Titanium and titanium alloy.,16-18(Wiley-VCH, Weinheim,(2003)

2. R. Boyer. Mater. Sci. Eng., A213, 103-114 (1996)

3. H. Zhou, B. Gabbitas, S. Matthews, D. Zhang, Proceedings of the 12th World Conference on Titanium, V3, 1906-1910 (2011)

4. K. Luthra, Oxidation of Metals, 36, 274-290 (1991)

5. S. Taniguchi, T. Shibata, S. Itoh, Materials transaction, 32, 151-156 (1991)

6. P. Fauchais, G. Montavon, G. Bertrand, J. Thermal Spray Technol., 19, 56-80 (2010) 
7. P. Fauchais, M. Fukumoto, A. Vardelle, J. Thermal Spray Technol., 13, 337-360 (2004)

8. J. Kawakita, S. Kuroda, T. Fukushima, H. Katanoda, Surf. Coat Technol., 201, 12501255 (2006)

9. H. Steffens, E. Erturk, K. Busse, J. Vac. Sci. Technol., A3, 2459-2463 (1985)

10. E. Lugscheider, P. Lu, B. Haeuser, D. Jaeger, Surf. Coat. Technol., 32, 215-226 (1987)

11. M. Jankovic, J. Mostaghimi, Plasma Chem. Plasma Process., 15, 607-628 (1995)

12. M. Morks, C.C. Berndt. Applied Surf. Sci., 256, $4322-4327$ (2010)

13. M. Planche, H. Liao, C. Coddet, Surf. Coat Technol., 202, 69-76 (2007)

14. M. Jankovic, J. Mostaghimi, V. Pershin, J. Thermal Spray Technol., 9, 114-120 (2000) 